\title{
Exploring the impact of sharing personal narratives of brain injury through film in Australian Indigenous
} communities

\author{
Susan Gauld, Sharon Smith, Melissa Bianca Kendall
}

\begin{abstract}
Aims: Culturally appropriate community education about brain injury prevention and supporting people with brain injury and their families is needed in Australian Indigenous communities. Narrative therapy offers a useful method in rehabilitation that may be particularly appropriate for Indigenous people. This paper aims to explore and describe the impact of sharing personal stories on film by Australian Indigenous families who have experienced acquired brain injury (ABI). Methods: Participatory Action Research approaches were used in the production of films describing personal stories of brain injury for three Australian Indigenous men and their families. Participants were involved in the conceptualization, development, filming and launch of the films in their own communities (one urban, one rural and one remote). The production of the films was followed by
\end{abstract}

Susan Gauld ${ }^{1}$, Sharon Smith ${ }^{1}$, Melissa Bianca Kendall2,3

Affiliations: ${ }^{1}$ Rehabilitation Coordinator Acquired Brain Injury Outreach Service, Princess Alexandra Hospital, Metro South Health, Brisbane, Queensland, Australia; ${ }^{2}$ Senior Research Officer, Acquired Brain Injury Outreach Service (ABIOS) and Transitional Rehabilitation Program (TRP), Princess Alexandra Hospital, Metro South Health, Brisbane, Queensland, Australia; ${ }^{3}$ Associate Professor, the Hopkins Centre, Griffith University/Division of Rehabilitation-Metro South Health, Queensland, Australia.

Corresponding Author: Melissa Bianca Kendall, Senior Research Officer, ABIOS and TRP, PO Box 6053, Buranda QLD Australia 4102; Email: mkkayzac12@gmail.com

Received: 08 January 2018

Accepted: 13 March 2018

Published: 30 March 2018 individual semi-structured interviews with film participants. Thematic analysis of interview data was undertaken. Results: While produced as an educational digital video disc (DVD) resource for improving brain injury prevention awareness and support in Australian Indigenous communities, participants identified five themes related to the benefits and challenges of the narrative filmmaking process, namely the motivation to tell their story, the experience of making the film, the social impact and benefits, the importance of the launch and the untold stories that remain. Conclusion: Storytelling by Australian Indigenous families through film was perceived by individuals with $A B I$ and their families to have important personal benefits in addition to providing a culturally relevant community education resource. A recognition of the film as merely a snapshot in time is necessary however and ongoing opportunities for storytelling should be sought. Community launches of such resources are important for supporting families affected by brain injury and increasing awareness in their communities.

Keywords: Acquired brain injury, Community education, Indigenous health, Narrative therapy, Storytelling

\section{How to cite this article}

Gauld S, Smith S, Kendall MB. Exploring the impact of sharing personal narratives of brain injury through film in Australian Indigenous communities. Edorium J Disabil Rehabil 2018;4:100037Do5SG2018.

Article ID: 100037Do5SG2018 


\section{EDORiUM Journals}

Edorium J Disabil Rehabil 2018;4:100037D05SG2018.

www.edoriumjournals.com/ej/dr

Gauld et al.

doi: 10.5348/100037Do5SG20180A

\section{INTRODUCTION}

Acquired Brain Injury (ABI) describes all types of damage to the brain that occur after birth and typically excludes neurodegenerative disorders. Most frequently this involves stroke or traumatic brain injury. ABI is a leading cause of disability globally resulting in longterm physical, cognitive, communication, social and behavioural deficits affecting not only individuals [1-3] but also families [4, 5] and communities [6, 7]. In Australia, rates of stroke and traumatic brain injury are particularly high in Aboriginal communities with the recorded rate of $\mathrm{ABI}$ at least three times higher for Australian Indigenous Peoples, than for non-indigenous people $[8-10]$. Further to this, it is highly likely that counts of disability prevalence in Australian Indigenous populations are significantly underestimated [11].

A systematic review of 26 international studies on Indigenous people with traumatic brain injury (TBI) found research gaps around level of injury and/or treatment, neuropsychological assessment, indigenous perspectives, interventions and rehabilitation [12]. This was especially the case for Indigenous Australians as compared to other nations (e.g. New Zealand and Canada). Further, despite the increased prevalence of ABI in Indigenous communities, the uptake of rehabilitation services after injury is extremely low [13].

Poor uptake of health services more generally by Australian Indigenous peoples has long been recognized as a key health challenge heralded by basic differences in concepts of health between indigenous and nonindigenous individuals [14]. Clearly, many health services are not meeting the needs of Indigenous consumers $[8,15-17]$. This occurs on a background of long term disenfranchisement of Australian Indigenous people [11] through colonisation, racism and marginalization. Indigenous people have diversity in languages and groups with different health concepts and varying trust in Western services. People are fearful of leaving families and country and travelling long distances for healthcare [8] therefore offering services away from remote communities is not the most appropriate model of service delivery for many Indigenous people.

Within the context of brain injury services, many Indigenous people do not specifically address their brain injury diagnosis as it is often merely one of a range of comorbidities [13]. Furthermore, the fact that some Indigenous people live in remote areas experiencing limited services, a lack of support, geographic isolation and significant travel distances means that accessing appropriate brain injury services is logistically more difficult [18]. In a review of brain injury services in
New South Wales, Australia, issues specific to access by Indigenous Australians included cultural issues of kinship and connection to community that impacted on acceptance of centre-based programmes requiring separation from family. Services were only engaged when trust had been established and this was difficult to develop because services were not based in many Australian Indigenous communities [19].

\section{Developing culturally appropriate services}

Traditionally, Australia has been good at identifying problems but deficient in developing solutions in Australian Indigenous health [20]. Townsend and colleagues [11] highlight that cultural perspectives on disability, a lack of culturally sound research methods and the absence of culturally appropriate assessment contribute to invisibility of Australian Indigenous peoples in health figures and equally the absence of appropriate health solutions. Calls have been made for community controlled, culturally appropriate, self-determining health solutions based on the goals of Indigenous communities [21-23]. Culturally safe services are required [24, 25]. There is a necessity to embrace difference and accept culture while acknowledging that specific communities and individuals will differ $[24,26]$. Incorporating the voice of Indigenous people in healthcare is an important link in promoting cultural safety [27] as is the incorporation of partnerships with Indigenous health workers in health promotion, education, liaison and delivery of clinical services [28].

Lakhani and colleagues [12] called for more research on brain injury within Australian Indigenous peoples to inform the evidence base. This evidence base should guide culturally safe and appropriate policy and practice related to health promotion and prevention, treatment and rehabilitation as well as raising community awareness around disability services through community education in culturally appropriate ways $[18,29]$.

In response to the identified need for culturally safe solutions for brain injury rehabilitation in Australian Indigenous communities, a three year Participatory Action Research (PAR) project was initially conducted by the current researchers in collaboration with two selfselected remote Australian Indigenous communities in Far North Queensland [30, 31]. Consultations occurred with key stakeholders in each community. One of the key findings of the consultations in both communities was the need for community-wide education about brain injury prevention and how to support someone with a brain injury and their family in their own community. To achieve this, a need for culturally appropriate and relevant brain injury education resources for Australian Indigenous communities was identified. The development of culturally relevant materials to support Indigenous communities is more likely to be effective when informed 


\section{EDORIUM Journals}

Edorium J Disabil Rehabil 2018;4:100037D05SG2018.

www.edoriumjournals.com/ej/dr

by participatory action, narrative therapy and critically reflective practice. In this way, collaborative partnerships in resource development will be fostered [8, 18, 32, 33].

\section{The potential of narrative therapy approaches in Australian Indigenous rehabilitation}

The importance of narrative therapy and research has been growing leading to a plethora of differentiated methodologies [34-36]. Core across narrative approaches is the intention to give voice to alternative stories, challenge dominant ideas and recognize strengths and capacities [32]. Narrative is both a mode of thought and a method of communication central to how humans understand themselves within a cultural world [36]. Stories bind together individual and collective memories and respect personal histories within cultural traditions. It is through narratives that people often come to terms with momentous events [37]. The translation of an emotional or traumatic event into a story or narrative is likely to have multiple physical and mental health benefits [38-43]. Therapeutic filmmaking as a form of narrative has been shown to promote positive experiences, mastery, shifts in perceptions, changed perspectives of self and interactions [44].

Australian Indigenous peoples have a rich tradition in storytelling or 'yarning' [45]. Indigenous narratives are typically oral in nature and based on personal experience or historical events [46]. It has been suggested that the narratives of Indigenous people are structurally different to narratives of non-indigenous people in that they are not necessarily chronological, interactive or anchored in context and may be intentionally vague, repetitive and without resolution [46].

Narratives have been used previously in Indigenous communities to study issues such as smoking in pregnancy [47]. Armstrong and colleagues [13] in a study of communication disorders highlighted the importance of yarning even in the context of limited speech and language difficulties. Wain and colleagues [27] provided a methodological account of collecting narratives (yarning data collection) and developed multimedia resources in the form of an open access online website with education resources developed from such yarns. Given the cultural relevance of narratives for Indigenous communities, this method seemed the most appropriate to explore in the development of an educational resource for communities. In the final year of the three year Participatory Action Research project, a plan was made to develop a digital video disc (DVD) as a community education tool based on the narratives of Australian Indigenous families following brain injury. Whilst the principal aim of the work was to have an end product that was useful as an educational resource to Australian Indigenous communities as identified within the earlier years of the project, an evaluative research component associated with the production of such a resource was considered integral. This paper reports on one aspect of this evaluation, exploring the benefits and challenges to the film participants of telling their stories so publicly.

\section{MATERIALS AND METHODS}

Participatory action research (PAR) represents a best practice response to the ethical concerns of research focusing on vulnerable populations such as Indigenous people [33]. PAR has been defined as an empowering process of reflective inquiry that researchers and participants undertake collectively to understand and improve life circumstances. The PAR process is directly linked to action taking into account history, culture, and local context and social relationships [48] and involves cycles of planning, acting and reviewing. The National Health and Medical Research Council of Australia recommend that all research with Australian Indigenous communities should be participatory and focused on outcome and benefits for the community [49]. Located within the final year of a larger three year PAR project, ethical clearance for this project was given through the relevant Human Research Ethics Committee. Based on the identified need within Australian Indigenous communities for culturally relevant resources, the plan to develop a DVD film as a community education tool was made in collaboration and partnership with the communities involved in the larger project. The film would be specifically for Australian Indigenous people with brain injury, their families, their communities, and those who work with and support them. It was determined, in collaboration with project stakeholders (ie people with brain injury, families, interested community members and local health workers) that the films needed to feature families living in a range of situations across the state (urban, regional and remote), to ensure appeal to a range of audiences, and a connection with as many potential viewers as possible.

Information about the proposal to develop a DVD was disseminated through community meetings in these communities and through information distributed by the Acquired Brain Injury Outreach Service involved in the project. Following the announcement of the proposal and based on their knowledge of the project, three men with brain injury and their families self-selected (volunteered) for participation in the DVD to tell their stories of brain injury. These three families were representative of the range of locations desired for the DVD. An individual series of questions were written in consultation with each family to assist with the flow of the story while filming. Each family decided who would participate in filming and this varied, but included the person with the ABI, and various family members. Filming involved the use of conversational narratives to assist with the 


\section{EDORiUM Journals}

Edorium J Disabil Rehabil 2018;4:100037D05SG2018.

www.edoriumjournals.com/ej/dr

Gauld et al. 4

story telling and depicted individuals engaging in life situations, such as scenes of family members interacting and individuals participating in leisure activities. A film crew assisted in the filming, editing and production, working with families and researchers collaboratively. Filming occurred in family's homes and communities, over a 1-2 day period with each story of different length and content. Following filming and editing, a 'draft' final version was provided to each family for comment on accuracy and appropriateness, allowing families to make any necessary changes. On completion of the final DVD, participants were involved to varying degrees in a 'launch' of each story, at locations chosen by the families involved. Launches typically included a public screening of the story, followed by a shared meal. The launch itself was an opportunity for storytelling and healing, and provided the opportunity for extended family and friends to publicly acknowledge the ABI event, the efforts of the injured person and his family, and their community.

After the launching of each story, and the distribution of the DVD, participants were interviewed about their experiences in the making, and launching of the films, and in the telling of their stories. The three men and at least one of their family members (e.g., parent) were interviewed either by phone or in person by independent interviewers not involved in the project. An interview guide was developed for the interviews (Table 1). The semi-structured interview questions aimed to elicit information about the impact of the experience on the person with brain injury, and the impact on their family members who participated. Interviews were recorded and interview data transcribed verbatim. Interview data was entered, managed and encoded using N-Vivo 8 [QSR International] to identify common themes. The first two authors completed a first read of the data to get an overall understanding of the broad issues discussed. Line by line coding was then undertaken by each of the first two authors resulting in over 30 codes. These codes were then collapsed into semantic themes and verified within the data by the third author. The whole process occurred over 8 months, from filming, to follow-up interviews.

\section{Table 1: Interview guide}

Why did you choose to tell your story on the DVD?

What was it like making the DVD?

What was it like seeing the finished DVD?

How has making the DVD impacted on your recovery?

How has making the DVD changed the way you see yourself?

What have other people said about the DVD?

What did you like or dislike about the launch of the DVD?

How did you feel once the filming and launch were finished?

Do you think it is worthwhile for other people to be involved in telling their story in this way?

\section{RESULTS}

Five themes emerged from thematic analysis of the collected interview data, namely (a) the motivation to tell their story; (b) the experience of making a film; (c) social impacts and benefits; (d) the importance of the launch; and (e) untold stories.

\section{Motivation to tell their story}

The current study found that these three families were motivated to tell their story. One family member expressed the view that Australian Indigenous People do not want to speak up, and tell their story, but she was glad to have done so to educate others. She was concerned that communities need to understand how a brain injury can occur, and the impact on the family and their involvement in the recovery process. She also stressed that the family learns as they experience the changes associated with brain injury - 'it's a very upsetting thing to live with' and she wants other families to understand how 'we feel alone and left out here and we just don't know how to cope'.

One man with ABI was glad he could tell his story, so that others understood what had happened to him, the effect on him, and the hard work he had to go through in his recovery. His family member valued the opportunity to tell his story, as a way to educate community members about the effects of a brain injury and the impact on the family. It was an opportunity to help people who know the family to better understand what they have had to go through. In the current study, one family member was motivated in two ways to tell her story - firstly to give hope to others, and secondly for herself, 'to get it out'. 'I didn't get counselling, nothing for that, and like speaking out like that sort of helped me too....helped both of us...... and that DVD may help someone else, because there is hope'. This cathartic process was observed by the project team during the filming and launching of the individual stories. The team included clinicians (Social Work and Occupational Therapy) with many years' experience in community based practice and family work, who were able to talk with family members about their reactions. The impact of telling their story on film for one family was significant. 'Everyone should tell their story... we went through depression, very stressful times, but doing this... we both sort of spoke and that sort of helped me a lot too, speaking out'.

\section{Experience of making a film}

Making a film was a significant experience for participants that created mixed emotions. The importance of having and being involved in the production of such a resource was personally relevant and outweighed the emotional effect of making the film for one family member. 'I had to relive the tragic incident...it was hard 


\section{EDORiUM Journals}

Edorium J Disabil Rehabil 2018;4:100037D05SG2018.

www.edoriumjournals.com/ej/dr

for me...but I think we've come through it really well...the DVD says it all'. She felt that the story reflected how far the family had come, with the support of extended family and others, and they are proud of what has been achieved.

The opportunity to share their narrative in a public forum was a unique experience for all participants. 'That was something good to do, something different for me to do...I'm not that type of person that would normally do something like that'. For one family, the experience was very emotional, speaking about the event for the first time in many years. This family also expressed a feeling of pride in what they had achieved together since the time of injury. Collectively, these findings suggest that participants were proud of the film and the role that they played in bringing the project to fruition. 'He enjoyed it... that he was making it for other families to understand exactly what he is going through, he was happy'.

\section{Social impact/benefits}

While the motivation to tell their story and the experience of the film were intensely personal influences of producing a film narrative, a number of social impacts and benefits were identified by participants. For the extended family unit, the process of making a film and telling their story allowed one family to reminisce about their journey together from time of injury. It provided an opportunity for the injured person to hear feedback from family on his past achievements and progress, a positive experience for him. Making the film gave one family an opportunity to talk about what the family went through with the person who was injured. This led to an increased understanding within the family. 'It was emotional for me and making it... both of us... helped us both, you know to bring everything out, what we had, you know, what we went through'. It also gave this family hope and enjoyment in telling their story, because it helps others. The positive impact of telling his story on film is reflected in the comment by an individual with ABI - 'It made me feel...a lot better than I was before.' Having the film on DVD as a resource for the family and individual with $\mathrm{ABI}$ was seen as a positive, in that it captured achievements up to a certain point in time, which could then be used in the future for comparison, and reflection. '..we focused on his strengths, you know, in his recovery, .... but I think the DVD is always there for him to reflect back on'.

Increased community understanding of their situation was reported by one family member, who reported that extended family and community members could now more fully understand what the person with ABI was capable of. She also reported that the film and its launch created increased interest in how her son was coping, and more people asked about him. 'I get that all the time, you know about him and how they ask about him, so I think it was really good that it was made'. The long term benefits of this resource and the impact on community are outlined in this quote - 'There's family, there is always family commitment, family support. We've even got community support for him, you know... if the community can get together and support each other, you can make a better community...'

\section{The importance of the launch}

The importance of having a launch in a location that allowed many family and community members to attend was important. The launch was the context within which personal injury became a community issue. One family member considered the benefits that this launch would bring to the whole community, an extension of her motivation to be involved in the whole project. 'I felt like it would be an excellent idea if we did take it back to his community because, you know, living on my community, I felt that there wasn't enough education around brain injury'. This motivation also had an impact on when the launch was held - '..it needed to be ... Brain Injury Awareness Week ... because all my years living home, I've never known that stuff to be talked about'.

The launches of the stories were emotional events for the families involved, with family members and others invited to speak. The launch was also a social event, involving friends, family and community members, and people of all ages. The impact of the launch on the person with ABI was positive-'...made me feel like I was somebody special'. 'They had a lot of respect for me'. 'He was very proud of the DVD and making sure different ones got copies'.

\section{Untold stories}

Despite each family being involved in decisions about content and the final editing of their stories, each family expressed some regret several months later about additional content they would have liked to include, such as the struggles and ongoing difficulties likely to be faced by the person with brain injury, as well as their family. This provided insight into the process, and the need to provide additional time post production for changes or additions. Accepting that the film is a snap-shot in time was difficult for some participants when the final resource may be viewed for many years after.

Sensitivity was needed in getting the right balance between the individual's (with ABI) story and the family's story. Whilst the families wanted to accurately report the enormous impact of the injury, all involved also wanted to focus on the achievements of the individual and family, without negatively impacting on the individual's feelings of self-worth, self-esteem, and selfimage. The outcome of this was that each story is told in a relatively positive manner, with some regret voiced about minimising the enormous stress and burden that was and is experienced by family. One family member said 'When I look back at it I wished I'd answered a 


\section{EDORiUM Journals}

Edorium J Disabil Rehabil 2018;4:100037D05SG2018.

www.edoriumjournals.com/ej/dr

Gauld et al. 6

couple of questions a bit different, because everybody needs to hear someone that has been through it, ...I felt straight up I didn't explain exactly how [my son] had the accident.' 'I think you could easily do an update'. '..what it is saying that we all chipped in and moved along.... but now we are at a different stage'. Some concern was expressed about the reaction and perception of others because of things unsaid. 'It could still sound like the family coped, if you didn't know us and you watched it, to me it sounds like that family really got it together and they're coping and he looks like he is doing well, but there is a lot of hidden stuff in there..'

\section{DISCUSSION}

Collectively, the current findings suggest that Australian Indigenous families derive benefits from sharing their stories through film in an endeavor to produce a culturally relevant community resource. Families are motivated to tell their stories, benefit from the experience of making the film, identify social benefits of the film and highlight the importance of the launch as a social community event. Medved and colleagues [50] have reported that, despite the common perception that Indigenous people do not want to speak out on public health issues, many participate in research to assist others and improve awareness in their communities. In a review of personal narrative approaches in brain injury, D'Cruz and colleagues [51] found four themes that are reflective of this motivation to tell their story, namely (a) expressing and communicating to others; (b) feeling validated by the act of someone listening; (c) reflecting and learning about oneself and (d) being productive. The findings highlight the benefits of participatory action research whereby researchers, individuals and communities work side by side for the greater good [52].

Researchers have identified feelings of mastery associated with therapeutic filmmaking [44] and the current study findings support this contention. Further, previous research with young people with cancer supports the benefits of having an ongoing resource created on the basis of one's personal experiences as a 'personal legacy' [53, 54]. In using narrative video for a young man with cancer, Pereira et al. [54] similarly found that such narratives are perceived to bring people closer through shared stories. In the current study, the opportunity to develop a narrative that didn't involve direct personal interaction with the community appeared to provide participants with a non-confrontational way of showing their community what brain injury meant for them. Similarly, others have found that internet blogs as narratives are a useful way to increase connectivity without the added concern of face to face social judgment [55]. In using a narrative Photovoice intervention for people with mental illness, Mizock et al. [41] similarly found that planning a recovery narrative exhibit, much like a launch and celebrating recovery narrative work within that launch were extremely important aspects of this type of narrative therapy.

Despite these identified benefits, participants in the current study identified that narrative through film tells a story at a snapshot in time. These findings highlight the need for ongoing opportunities for narrative expression. Indeed, narrative is an ongoing process rather than a 'finished product' and may change across time [56]. This may be particularly so for Australian Indigenous peoples whose narratives take on a different structure and focus [46].

\section{CONCLUSION}

Storytelling on film was used in this study to create a culturally appropriate educational resource (DVD) about brain injury for Australian Indigenous communities, a need identified as part of a larger participatory action project. This approach to resource development offers significant perceived benefits to the individual with brain injury, and their families in telling their stories and sharing these stories with their communities. Some families are motivated to tell their story, and enjoyed the experience of making a film. There are identified individual, familial and community benefits of the resource as well as the participatory process involved in its production. The importance of the launch for community involvement and engagement was recognized. The benefits of this form of storytelling however need to be balanced with the recognition that film offers a snapshot of a family's journey and should be supplemented by other means through which ongoing storytelling can occur.

\section{REFERENCES}

1. Ponsford JL, Downing MG, Olver J, et al. Longitudinal follow-up of patients with traumatic brain injury: Outcome at two, five, and ten years post-injury. J Neurotrauma 2014 Jan 1;31(1):64-77.

2. Sinha S, Gunawat P, Nehra A, Sharma BS. Cognitive, functional, and psychosocial outcome after severe traumatic brain injury: A cross-sectional study at a tertiary care trauma center. Neurol India 2013 SepOct;61(5):501-6.

3. Crichton SL, Bray BD, McKevitt C, Rudd AG, Wolfe CD. Patient outcomes up to 15 years after stroke: Survival, disability, quality of life, cognition and mental health. J Neurol Neurosurg Psychiatry 2016 Oct;87(10):1091-8.

4. Whiffin CJ, Bailey C, Ellis-Hill C, Jarrett N, Hutchinson PJ. Narratives of family transition during the first year post-head injury: Perspectives of the non-injured members. J Adv Nurs 2015 Apr;71(4):849-59.

5. Manskow US, Sigurdardottir S, Røe C, et al. Factors affecting caregiver burden 1 year after severe traumatic brain injury: A prospective nationwide 


\section{EDORIUM Journals}

multicenter study. J Head Trauma Rehabil 2015 Nov-Dec;30(6):411-23.

6. Humphreys I, Wood RL, Phillips CJ, Macey S. The costs of traumatic brain injury: A literature review. Clinicoecon Outcomes Res 2013 Jun 26;5:281-7.

7. Frost RB, Farrer TJ, Primosch M, Hedges DW. Prevalence of traumatic brain injury in the general adult population: Ameta-analysis. Neuroepidemiology 2013;40(3):154-9.

8. Hersh D, Armstrong E, Bourke N. A narrative analysis of a speech pathologist's work with Indigenous Australians with acquired communication disorders. Disabil Rehabil 2015;37(1):33-40.

9. Jamieson LM, Harrison JE, Berry JG. Hospitalisation for head injury due to assault among Indigenous and non-Indigenous Australians, July 1999 - June 2005. Med J Aust 2008 May 19;188(10):576-9.

10. Katzenellenbogen JM, Vos T, Somerford P, Begg $\mathrm{S}$, Semmens JB, Codde JP. Burden of stroke in Indigenous Western Australians: A study using data linkage. Stroke 2011 Jun;42(6):1515-21.

11. Townsend C, White P, Cullen J, Wright CJ, Zeeman H. Making every Australian count: Challenges for the national disability insurance scheme (NDIS) and the equal inclusion of homeless Aboriginal and Torres Strait Islander peoples with neurocognitive disability. Aust Health Rev 2017 Mar 30.

12. Lakhani A, Townsend C, Bishara J. Traumatic brain injury amongst Indigenous people: A systematic review. Brain Inj 2017;31(13-14):1718-30.

13. Armstrong E, Hersh D, Hayward C, Fraser J. Communication disorders after stroke in Aboriginal Australians. Disabil Rehabil 2015;37(16):1462-9.

14. Vass A, Mitchell A, Dhurrkay Y. Health literacy and Australian Indigenous peoples: An analysis of the role of language and worldview. Health Promot J Austr 2011 Apr;22(1):33-7.

15. Armstrong E, Hersh D, Hayward C, Fraser J, Brown M. Living with aphasia: Three Indigenous Australian stories. Int J Speech Lang Pathol 2012 Jun;14(3):27180.

16. Lowell A, Maypilama E, Yikaniwuy S, Rrapa E, Williams R, Dunn S. "Hiding the story": Indigenous consumer concerns about communication related to chronic disease in one remote region of Australia. Int J Speech Lang Pathol 2012 Jun;14(3):200-8.

17. McBain-Rigg KE, Veitch C. Cultural barriers to health care for Aboriginal and Torres Strait Islanders in Mount Isa. Aust J Rural Health 2011 Apr;19(2):70-4.

18. Keightley ML, Ratnayake R, Minore B, et al. Rehabilitation challenges for Aboriginal clients recovering from brain injury: A qualitative study engaging health care practitioners. Brain Inj 2009 Mar;23(3):250-61.

19. Mitsch V, Curtin M, Badge H. The provision of brain injury rehabilitation services for people living in rural and remote New South Wales, Australia. Brain Inj 2014;28(12):1504-13.

20. McCalman J, Tsey K, Wenitong M, et al. Indigenous men's support groups and social and emotional wellbeing: A meta-synthesis of the evidence. Aust $\mathrm{J}$ Prim Health 2010;16(2):159-66.
21. McLennan V, Khavarpour F. Culturally appropriate health promotion: Its meaning and application in Aboriginal communities. Health Promot J Austr 2004;15:237-9.

22. Mikhailovich K, Morrison P, Arabena K. Evaluating Australian Indigenous community health promotion initiatives: A selective review. Rural Remote Health 2007 Apr-Jun;7(2):746.

23. Reeve CA, De La Rue S, McBain KE, Solomon S, Felton-Busch C. Indigenous Lifescripts - a tool for modifying lifestyle risk factors for chronic disease. Aust Fam Physician 2008 Sep;37(9):750-1, 753-4.

24. Kendall E, Marshall CA. Factors that prevent equitable access to rehabilitation for Aboriginal Australians with disabilities: The need for culturally safe rehabilitation. Rehabilitation Psychology 2004;49(1):5-13.

25. Barnett L, Kendall E. Culturally appropriate methods for enhancing the participation of Aboriginal Australians in health-promoting programs. Health Promot J Austr 2011 Apr;22(1):27-32.

26. Ariotti L. Social construction of Anangu disability. Aust J Rural Health 1999 Nov;7(4):216-22.

27. Wain T, Sim M, Bessarab D, Mak D, Hayward C, Rudd C. Engaging Australian Aboriginal narratives to challenge attitudes and create empathy in health care: A methodological perspective. BMC Med Educ 2016 Jun 2;16:156.

28. Hooper K, Thomas Y, Clarke M. Health professional partnerships and their impact on Aboriginal health: An occupational therapist's and Aboriginal health worker's perspective. Aust J Rural Health 2007 Feb;15(1):46-51.

29. Green A, Abbott P, Delaney P, et al. Navigating the journey of Aboriginal childhood disability: A qualitative study of carers' interface with services. BMC Health Serv Res 2016 Dec 1;16(1):680.

30. Gauld S, Smith S, Kendall MB. Using participatory action research in community-based rehabilitation for people with acquired brain injury: From service provision to partnership with Aboriginal communities. Disabil Rehabil 2011;33(19-20):1901-11.

31. Friday C, Accoom J, Smith S, Gauld S. Nyunu dukul kiru ngakaku (looking after your brain): Brain injury project in Far North Queensland. Aborig Isl Health Work J 2008;32(5):4-6.

32. Smith S, O'Grady L, Cubillo C, Cavanagh S. Using culturally appropriate approaches to the development of Kidsmatter resources to support the social and emotional wellbeing of Aboriginal children. Australian Psychologist 2017;52:299-305.

33. Keightley M, Kendall V, Jang SH, et al. From health care to home community: An Aboriginal community-based ABI transition strategy. Brain Inj 2011;25(2):142-52.

34. Smith B, Sparkes AC. Contrasting perspectives on narrating selves and identities: An invitation to dialogue. Qualitative Research 2008;8(2):5-35.

35. Fraas MR, Calvert M. The use of narratives to identify characteristics leading to a productive life following acquired brain injury. Am J Speech Lang Pathol 2009 Nov;18(4):315-28.

36. Brockmeier J. Narrative scenarios: Toward a culturally thick notion of narrative. In: Valsiner J, editor. The 


\section{EDORIUM Journals}

Oxford Handbook of Culture and Psychology. Oxford, UK: Oxford University Press; 2012. p. 439-67.

37. Charon R. Narrative Medicine: Honoring the Stories of Illness. New York: Oxford University Press; 2006.

38. Pennebaker JW. Telling stories: The health benefits of narrative. Lit Med 2000 Spring;19(1):3-18.

39. Pennebaker JW, Seagal JD. Forming a story: The health benefits of narrative. J Clin Psychol 1999 Oct;55(10):1243-54.

40. Hargrave TD. Using video life reviews with older adults. Journal of family therapy 1994;16(3):259-68.

41. Mizock L, Russinova Z, DeCastro S. Recovery narrative photovoice: Feasibility of a writing and photography intervention for serious mental illnesses. Psychiatr Rehabil J 2015 Sep;38(3):279-82.

42. Smith B, Tomasone JR, Latimer-Cheung AE, Martin Ginis KA. Narrative as a knowledge translation tool for facilitating impact: Translating physical activity knowledge to disabled people and health professionals. Health Psychol 2015 Apr;34(4):303-13.

43. Ulatowska HK, Reyes B, Santos TO, Garst D, Vernon $\mathrm{J}$, McArthur J. Personal narratives in aphasia: Understanding narrative competence. Top Stroke Rehabil 2013 Jan-Feb;2O(1):36-43.

44. Johnson JL, Alderson KG. Therapeutic filmmaking: An exploratory pilot study. The Arts in Psychotherapy 2008;35(1):11-19.

45. Bessarab D, Ng'andu B. Yarning about yarning as a legitimate method in indigenous research. Int $\mathrm{J}$ Crit Indig Stud 2010;3:37-50.

46. Walsh M. Ten postulates concerning narrative in Aboriginal Australia. Narrative Inquiry 2016;26(2):193-216.

47. Gould GS, Bovill M, Clarke MJ, Gruppetta M, CadetJames Y, Bonevski B. Chronological narratives from smoking initiation through to pregnancy of Indigenous Australian women: A qualitative study. Midwifery 2017 Sep;52:27-33.

48. Baum F, MacDougall C, Smith D. Participatory action research. J Epidemiol Community Health 2006 Oct;60(10):854-7.

49. National health and medical research Council. The NHMRC road map: A strategic framework for improving aboriginal and torres strait islander health through research and final report of community consultations on the NHMRC road map. 2002. [Available at: www.nhmrc.gov.au/guidelinespublications/r27-r28]

50. Medved MI, Brockmeier J, Morach J, ChartierCourchene L. Broken heart stories: Understanding Aboriginal women's cardiac problems. Qual Health Res 2013 Dec;23(12):1613-25.

51. D'Cruz K, Douglas J, Serry T. Personal narrative approaches in rehabilitation following traumatic brain injury: A synthesis of qualitative research. Neuropsychol Rehabil 2017 Aug 9:1-20.

52. Wallerstein NB, Duran B. Using community-based participatory research to address health disparities. Health Promot Pract 2006 Jul;7(3):312-23.
53. Akard TF, Dietrich MS, Friedman DL, et al. Digital storytelling: An innovative legacy-making intervention for children with cancer. Pediatr Blood Cancer 2015 Apr;62(4):658-65.

54. Pereira LM, Muench A, Lawton B. The impact of making a video cancer narrative in an adolescent male: A case study. The Arts in Psychotherapy 2017;55:195-201.

55. Chung DS, Kim S. Blogging activity among cancer patients and their companions: Uses, gratifications and predictors of outcomes. Journal of the American Society for Information Science and Technology 2007;59(2):297-306.

56. Fivush R. Storying the self: A view on autobiography from developmental psychology. a/b: Auto/Biography Studies 2017;32(2):243-6.

$* * * * * * * * *$

\section{Acknowledgements}

We would like to acknowledge the contributions of the Australian Indigenous communities who participated in the research and production of the DVD and the provision of funding for the DVD by the Motor Accident Insurance Council of Queensland (MAIC).

\section{Author Contributions}

Susan Gauld - Substantial contributions to conception and design, Acquisition of data, Analysis and interpretation of data, Drafting the article, Revising it critically for important intellectual content, Final approval of the version to be published

Sharon Smith - Substantial contributions to conception and design, Acquisition of data, Analysis and interpretation of data, Drafting the article, Revising it critically for important intellectual content, Final approval of the version to be published

Melissa Bianca Kendall - Substantial contributions to conception and design, Analysis and interpretation of data, Drafting the article, Revising it critically for important intellectual content, Final approval of the version to be published

\section{Guarantor of Submission}

The corresponding author is the guarantor of submission.

\section{Source of Support}

None

\section{Consent Statement}

Written informed consent was obtained from the patient for publication of this study. 


\section{EDORiUM Journals}

Edorium J Disabil Rehabil 2018;4:100037D05SG2018.

Gauld et al. 9

www.edoriumjournals.com/ej/dr

\section{Conflict of Interest}

The authors were all employed at the Acquired Brain Injury Outreach Service where this study was conducted at the time it was conducted.

\section{Copyright}

(C) 2018 Susan Gauld et al. This article is distributed under the terms of Creative Commons Attribution
License which permits unrestricted use, distribution and reproduction in any medium provided the original author(s) and original publisher are properly credited. Please see the copyright policy on the journal website for more information.
Access full text article on other devices

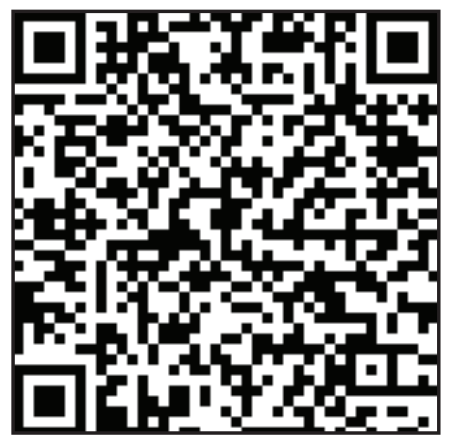

Access PDF of article on other devices

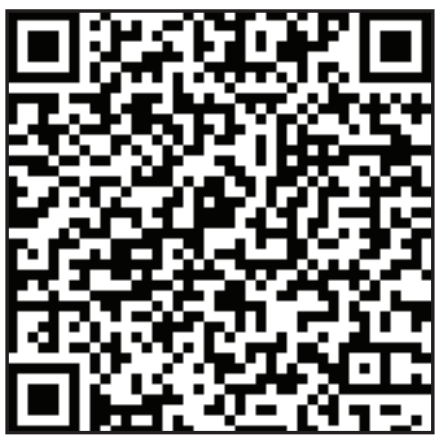

